\title{
Financial Market Liberalization, Monetary Policy, And Housing Sector Dynamics
}

\author{
Rangan Gupta, University of Pretoria, South Africa \\ Marius Jurgilas, Norges Bank, Norway \\ Stephen M. Miller, University of Nevada, Las Vegas, USA \\ Dylan Van Wyk, graduate student, University of Pretoria, South Africa
}

\begin{abstract}
This paper considers how monetary policy, a Federal funds rate shock, affects the dynamics of the US housing sector and whether the financial market liberalization of the early 1980's influenced those dynamics. The analysis uses impulse response functions obtained from a large-scale Bayesian vector autoregressive model at the national and four census regions. Overall, a 100 basis point Federal funds rate shock produces larger effects on real house prices, both at the regional level and the national level, in the post-liberalization period when compared to the preliberalization era. While the precision of the estimates do not imply significant differences, the finding does offer a caution. That is, the housing market appears more sensitive to monetary policy shocks in the post-liberalization period. Thus, the monetary authorities may need to exercise more care in implementing Federal funds rate adjustments going forward. Finally, we find that the reaction of housing sector proves heterogeneous across regions.
\end{abstract}

Keywords: Financial Market Liberalization; Monetary Policy; Housing Sector Dynamics; Large-Scale BVAR Models

\section{INTRODUCTION}

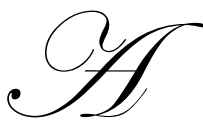

number of papers (e.g., Green 1997, Iacoviello 2005, Case et al. 2005, Rapach and Strauss 2006, Leamer 2007, Pariès and Notarpietro 2008, Vargas-Silva 2008a, Bao et al. 2009, Christensen et al. 2009, Ghent 2009, Ghent and Owyang 2009, Pavlidis et al. 2009, Iacoviello and Neri 2010) show a strong link between the housing market and economic activity in the US. Stock and Watson (2003) argue that houseprice movements lead real activity, inflation, or both, and, hence, can indicate where the economy will head. Moreover, the recent emergence of boom-bust cycles in house prices cause much concern and interest amongst policy makers (Borio et al. 1994; Bernanke and Gertler, 1995, 1999), since the bust of house price bubbles always lead to significant contractions in the real economy, vouched for by the current economic downturn. Given this, a thorough analysis of the effects of monetary policy on asset prices in general, and house prices in particular, will, in turn, lead to better understanding of the effects of monetary policy on the larger economy.

This paper considers how monetary policy, a Federal funds rate (FFR) shock, affects the dynamics of the US housing sector and whether the financial market liberalization of the early 1980's influenced those dynamics. Stock and Watson (2004), Rapach and Strauss (2007, 2009), Vargas-Silva (2008b) and Das et al. (forthcoming, 2009,2010 ) report evidence that numerous economic variables, such as, income, interest rates, construction costs, labor market variables, stock prices, industrial production, and consumer confidence index potentially predict movements in house prices and the housing sector. Thus, we estimate a large-scale Bayesian vector-autoregressive (LBVAR) model that incorporates 143 monthly macroeconomic variables over the periods 1968:01 to 1982:12 and 1989:01 to 2003:12, including 21 housing-sector variables at the national and four census regions. The analysis uses impulse response functions obtained from the LBVAR model. We examine the model over these two periods to determine the effects, if any, from the liberalization of the US financial markets on the sensitivity of house prices to interest rate changes. 
The data set contains 21 variables relating to the housing sector, namely, housing starts, total new private housing units, mobile-home shipments, home sales, and home prices at the national level and housing starts, housing permits, home sales, and home prices at the four census regions (Northeast, Midwest, South, and West) of the US. As such, the dynamic analysis considers not only how monetary policy affects the housing sector at the national level but also in the four sub-regions.

We end the first period in 1982, given evidence that financial market liberalization started in the US circa 1982 (Iacoviello and Neri 2010; Campbell and Hercowitz 2005; and Dynan et al. 2006). ${ }^{1}$ We start the second period in 1989 to allow for a transition to the new regime with more liberalized financial markets. We end the second period at the end point of the sample in the Stock and Watson (2005) dataset that we use for our estimation. In this way, we define two periods of equal length - the period from 1968 to 1982, which measures the US market prior to financial market liberalization, and the period from 1989 to 2003, which measures the market after liberalization.

Similar to the large Bayesian vector autoregressions (LBVAR), Bernanke et al. (2005) proposed the factoraugmented VAR (FAVAR) approach to handle large amounts of data. The FAVAR approach extracts a few latent common factors from a large matrix of many economic variables, with the latent factors capturing the same information content of the original data set without confronting degrees of freedom problems. Our preference of the LBVAR over the FAVAR reflects the different requirements that these models exhibit with regard to the use of stationary and non-stationary data. The FAVAR approach requires stationary data so that the required data transformations create first-differences or growth rate versions of the variables under consideration. The LBVAR methodology, based on the appropriate design of the priors, handles non-stationary data without making data transformations, and, in the process, retains the variables in their original form. Moreover, as recently shown by Banbura et al. (2010), based on the Stock-Watson data set, the LBVAR model provides better forecasts of key macroeconomic variables. Beck et al. $(2000,2004)$ corroborate this view, when they note that forecasting becomes the root of inference and prediction in time-series analysis. Further, Clements and Hendry (1998) argue that in timeseries models, estimation and inference essentially mean minimizing of the one-step (or multi-step) forecast errors, Therefore, establishing a model's superiority implies that it produces smaller forecast errors than its competitors.

We use both regional and national housing sector data, since the effect of monetary policy on the economy differs according to regions and since economic conditions prevailing during a monetary policy shock do not necessarily correlate perfectly across regions (Carlino and DeFina 1998, 1999, and Vargas-Silva 2008b). We also can now test for consistency of the results over different regions and for whether any of the regions drive the US housing market.

Although this paper provides the first analysis of the effects of monetary policy on the US housing sector using a LBVAR model, many other studies examine the effect of monetary policy on housing. See, for example, Falk (1986), Chowdhury and Wheeler (1993), Iacoviello (2002), McCarthy and Peach (2002), Iacoviello and Minetti (2003, 2008), Ahearne et al., (2005), Ewing and Wang (2005), Kasai and Gupta (2010), Vargas-Silva (2008a, b), Gupta et al. (2010), and Gupta and Kabundi (2010) for analyses of the effect of monetary policy shocks on housing

\footnotetext{
${ }^{1}$ Iacoviello and Neri (2010) argue that financial liberalization started with the Garn-St. Germain Act of 1982, which deregulated the savings and loan industry, while Campbell and Hercowitz (2005) note that "The market innovations that followed the Monetary Control Act of 1980 and the Garn-St. Germain Act of 1982 relaxed collateral constraints on household debt." (p. 1). Dynan et al. (2006) suggest that from the late 1970's to the early 2000's, businesses experienced far more extensive direct access to the financial markets. Financially weaker firms that in the past could not raise funds could now do so via "the development of an active market for high-risk debt (sometimes known as "junk bonds')." (p. 127). "New issuance of junk bonds was essentially nil in the mid-1970s but accounted for more than 25\% of total non-financial bond issuance by 1984 and $42 \%$ in 2004. In addition, the share of capital expenditures undertaken by junk-rated firms climbed from a presumably low value in the mid-1970s to $5 \%$ in 1984 and 17\% in 2004." (p. 127). These market changes in conjunction with changes in government policies (like the abolition of interest rate ceilings on deposit accounts in the early 1980's) greatly increased the funds available for lending. At the same time that 'easy money' became available, households and businesses increased their propensity to borrow. Dynan et al. (2006) show that "The ratio of household debt to disposable personal income (DPI) rose from 0.57 in 1960 to 0.64 in 1984 and 1.14 in 2004 ; personal bankruptcy filings per 100,000 people climbed from 68 in 1960 to 120 in 1984 and 531 in 2004”. (p. 128).
} 
in the US, Europe, and South Africa. ${ }^{2}$ All these studies, except Vargas-Silva (2008b), ${ }^{3}$ Gupta et al. (2010), and Gupta and Kabundi (2010), who use a FAVAR approach, rely on a reduced-form vector autoregressive (VAR) model, a vector error-correction (VEC) model, or a structural VAR (SVAR) model, which, in turn, limits the number of variables included to conserve on the degrees of freedom. As indicated above, a large number of variables potentially affect monetary policy and the housing market. Thus, as Vargas-Silva (2008b) argues, not including all such variables can produce puzzling results due to the omission of important information (Walsh, 2000). Moreover, the restrictions on the number of included variables causes the authors often arbitrarily to choose specific variables to measure theoretical concepts such as economic activity or inflation, which may not perfectly reflect the selected concepts. Using techniques that permit the inclusion of large numbers of variables increases the probability that the theoretical concepts actually appear in the estimated model. In addition, previous studies can only generate impulse response functions (IRFs) for those few variables chosen in the model, which would generally mean analyzing only one housing-market variable. The LBVAR model addresses all of the above mentioned problems.

The analysis in Gupta and Kabundi (2010) most closely relates to our work. They assess, using the FAVAR modeling approach, the effects of monetary policy on house price inflation for the nine census divisions of the US economy, using a 126-variable data set of quarterly series from 1976:01 to 2005:02. ${ }^{4}$ Our paper extends this study by considering the possible differences in the dynamic adjustment due to monetary policy before and after the financial market liberalizations of the early 1980 s and by ensuring that the variables retain their original structure, given our usage of the Bayesian methodology. ${ }^{5}$

Our econometric analysis focuses on impulse response functions given a 100-basis point increase in the FFR. We find that across the four regions and the aggregate US economy, monetary policy changes exert a larger effect on real house prices in the post-liberalization period when compared to the pre-liberalization period. While the precision of the estimates do not imply significant differences, the finding does offer a caution. That is, the housing market appears more sensitive to monetary policy shocks in the post-liberalization period. On the one hand, this suggests that monetary policy possesses increased leverage. On the other hand, the housing market cycle traditionally contributes an important component to the aggregate business cycle. Thus, the monetary authorities may need to exercise more care in implementing FFR adjustments going forward. At the regional level, we conclude that prior to liberalization, the housing sector in the Midwest provides the underlying force that drives the national data, while after 1989 the housing sector in the South drives the national data. In other words, the impulse responses in the Midwest and South more closely match those of the national housing sector than the other regions before 1982 and after 1989, respectively. The West differs the most from the other regions in both periods.

We organize the rest of the paper as follows. Section 2 outlines the theory behind the LBVAR model. Section 3 describes the data. Section 4 identifies our a priori expectations and reports the impulse response functions findings. Section 5 concludes.

\footnotetext{
${ }^{2}$ Iacoviello and Minetti (2003) also use a calibrated dynamic stochastic general equilibrium (DSGE) model to analyze the effect of monetary policy on the US house price index. More recently, Iacoviello and Neri (2010) employ a more elaborate, estimated DSGE model for this purpose. They restrict the model, however, using only 10 macroeconomic variables and including only four housing-market variables. Gupta et al. (forthcoming) show that although the DSGE model of Iacoviello and Neri (2010) does not perform well in out-of-sample forecasting, it does achieve the best performance in predicting the turning point in the US house price index in 2006.

${ }^{3}$ Vargas-Silva (2008b) studies the effects of monetary policy on seven housing market variables that include housing starts, housing permits, and mobile home shipments, using a dataset of 120 monthly indicators.

${ }^{4}$ Gupta et al. (2010) analyze the effect of monetary policy on real house price growth in South Africa, using a large data set including 246 quarterly series over the period 1980:01 to 2006:04.

${ }^{5}$ Unlike Gupta and Kabundi (2010), since monthly house price data in the nine census regions do not exist prior to 1991, we only use monthly house price information from the four census divisions and the aggregate US economy, which, in turn, becomes available at the beginning of 1968 .
} 


\section{BASICS OF THE LBVAR ${ }^{6}$}

Let $Y_{t}=\left(y_{1, t} y_{2, t} \ldots y_{n, t}\right)^{\prime}$ equal a vector of random variables. We specify a $\operatorname{VAR}(p)$ model of these variables as follows:

$$
Y_{t}=c+A_{1} Y_{t-1}+\ldots+A_{p} Y_{t-p}+u_{t}
$$

where $c=\left(c_{1}, \ldots, c_{n}\right)^{\prime}$ equals an $n$-dimensional vector of constants, $A_{1}, \ldots, A_{p}$ equal $n \times n$ autoregressive matrices, and $u_{t}$ equals an $n$-dimensional white noise process with covariance matrix $E u_{t} u_{t}^{\prime}=\Psi$.

The VAR model generally uses equal lag lengths for all the variables of the model. Thus, the researcher must estimate many parameters, including many insignificant ones. This over-parameterization problem, resulting in multicollinearity and a loss of degrees of freedom, leads to inefficient estimates. One solution, often adopted, simply excludes lags with insignificant coefficients. Another approach uses a near VAR, which specifies unequal numbers of lags for the different variables within and across equations. Alternatively, Litterman (1986) proposes a BVAR model. Instead of eliminating longer lags, the Bayesian method imposes prior restrictions on these coefficients by assuming that they more likely equal zero than the coefficients on shorter lags. If, however, strong effects from less important variables exist, then the data can override this assumption. The restrictions conform to normal prior distributions with zero means and small standard deviations for all coefficients with the standard deviation decreasing as the lags increase. The exception, the coefficient on the first own lag of the dependent variable in each equation assumes a mean of unity. Litterman (1981) uses a diffuse prior for the constant. This specification is popularly referred to as the 'Minnesota prior' due to its development at the University of Minnesota and the Federal Reserve Bank at Minneapolis. The prior restrictions impose the following moments for the prior distribution of the coefficients:

$$
E\left[\left(A_{k}\right)_{i j}\right]=\left\{\begin{array}{cc}
\delta_{i}, & j=i, k=1 \\
0, & \text { otherwise }
\end{array}, V\left[\left(A_{k}\right)_{i j}\right]=\left\{\begin{array}{cc}
\lambda^{2} / k^{2}, & j=i \\
\lambda^{2} \sigma_{i}^{2} / k^{2} \sigma_{j}^{2}, & \text { otherwise }
\end{array}\right.\right.
$$

We assume in equation (2) that the coefficients $A_{1}, \ldots, A_{p}$ are independent and normally distributed. As discussed above, Litterman's (1986) original specification sets $\delta_{i}=1$ for all $i$, implying that all variables exhibit high persistence. If the researcher believes that some of the variables experience substantial mean reversion, however, the researcher can impose $\delta_{i}=0$, wherever necessary.

The hyperparameter $\lambda$ in equation (2) controls the overall tightness of the prior distribution near $\delta_{i}$. Alternatively, $\lambda$ determines the importance of the prior beliefs in relation to the information contained in the data. When $\lambda=0$, the posterior equals the prior and the data exert no influence on the estimation. When $\lambda=\infty$, no influence of the prior exists and, hence, the parameter estimates coincide with the ordinary least squares (OLS) estimates. The factor $1 / k^{2}$ equals the rate by which the prior variance decreases as the lag length of the VAR increases, and $\sigma_{i}^{2} / \sigma_{j}^{2}$ accounts for the scale difference and data variability. The coefficient $\vartheta \in(0,1)$ governs the extent to which the lags of other variables are "less important" relative to the own lags.

\footnotetext{
${ }^{6}$ This section relies heavily on the discussion available in Banbura et al. (2010) and Bloor and Matheson (2010). We retain their symbolic notations.
} 
To analyze the impulse responses of the housing market variables following a monetary policy shock, one must incorporate possible correlation among the residual of the different variables. Following Kadiyala and Karlsson (1997) and Sims and Zha (1998), we impose a normal prior distribution for the coefficients and an inverted Wishart prior distribution for the covariance matrix of the residuals, alternatively called the inverse-Wishart prior. This can occur when $\vartheta=1$.

The common practice of specifying VARs in first differences causes Doan et al. (1984) to propose another modification of the Minnesota prior -- the sums of coefficients prior. Consider equation (1) in its error-correction form as follows:

$$
\Delta Y_{t}=c-\left(I_{n}-A_{1}-\ldots-A_{p}\right) Y_{t-1}+B_{1} \Delta Y_{t-1}+\ldots+B_{p-1} \Delta Y_{t-p+1}+u_{t}
$$

The sums-of-coefficients prior imposes the restrictions that $\left(I_{n}-A_{1}-\ldots-A_{p}\right)$ equals the null or zero matrix. We use a hyperparameter $\tau$ to control the degree of shrinkage of the sums-of-coefficients prior. ${ }^{7}$ As $\tau$ goes to zero, the VAR model increasingly satisfies the prior, while as $\tau$ goes to $\infty$, the prior exerts no influence on the VAR model. Following Litterman (1986) and Sims and Zha (1998), we set the prior for the scale parameter $\sigma_{i}^{2}$ equal to the residual variance from a univariate autoregression of order $p$ for $y_{i t}$. Similarly, we determine the prior for the average of $y_{i t}$ (i.e., governed by the parameter $\mu_{i}$ ) as the sample average of the variable $y_{i t}$.

Since the LBVAR with the sums-of-coefficients and Minnesota priors produce better forecasts for key macroeconomic variables relative to the LBVAR model based on only the Minnesota prior, ${ }^{8}$ we use the former for our structural analysis discussed below. ${ }^{9}$ Further, for the LBVAR with only the Minnesota prior, the posterior coverage intervals of the impulse response functions become wider two years after the shock, and eventually explode. De Mol et al. (2008) argues that the overall tightness governed by $\lambda$ should reflect the size of the system - as the number of variables increases, the parameters should shrink to avoid overfitting. To select the values for $\lambda$ and $\tau$, we use the following algorithm due to Banbura et al. (2010). First, select $n^{*}\left(n^{*}<n\right)$ variables as benchmarks to evaluate the in-sample fit. We also follow Banbura et al. (2010) and choose three variables -employment, the consumer price index, and the Federal funds rate. Second, evaluate the in-sample fit with these $n^{*}$ variables of the OLS-estimated VAR model. Third, set $\tau$ proportional to $\lambda$ as $\tau=10 \lambda$, matching Banbura et al. (2010). Finally, choose $\lambda$ and $\tau$ to execute the same in-sample fit as the benchmark VAR based on the $n^{*}$ variables.

Specifically, for a desired Fit, we choose $\lambda$ such that

$$
\lambda(\text { Fit })=\arg \min _{\lambda}\left|F i t-\frac{1}{3} \sum_{i=1}^{3} \frac{M S E_{i}^{w}}{M S E_{i}^{0}}\right|,
$$

where $M S E_{i}^{\lambda}=\sum_{t=p}^{T_{0}-2}\left(y_{i, t+1 \mid t}^{\lambda}-y_{i, t+1}\right)^{2} /\left(T_{0}-p-1\right)$, That is, $M S E_{i}^{\lambda}$ equals the one-step-ahead mean squared error evaluated using the training sample, which, in our case, equals 1970:01 to 1979:12, and $t=1, \ldots, T_{0}-1$, where $T_{0}$ equals the beginning of the sample period and $p$ is the order of the VAR. Thus, $M S E_{i}^{0}$ equals the MSE of

\footnotetext{
${ }^{7}$ See equation (7) in Bloor and Matheson (2010) for further details.

${ }^{8}$ Banbura et al. (2010) find the same results.

${ }^{9}$ The authors will provide the forecast performance of the alternative BVARs for the key macroeconomic variables upon request.
} 
variable $i$ with the prior restriction imposed exactly (i.e., $\lambda=0$ ), while the baseline Fit equals the average relative MSE from an OLS-estimated VAR containing the three variables. That is,

$$
F i t=\frac{1}{3} \sum_{i=1}^{3}\left(M S E_{i}^{\infty} / M S E_{i}^{0}\right) .
$$

Finally, given the priors, we estimate the BVAR model using Theil's (1971) mixed estimation technique. Essentially, the method involves supplementing the data with prior information on the distribution of the coefficients. The number of observations and degrees of freedom increase by one, in an artificial way, for each restriction imposed on the parameter estimates. The loss of degrees of freedom due to over-parameterization associated with a classical VAR model, therefore, does not arise in the BVARs.

\section{DATA}

We use the data set of Stock and Watson (2005), which includes 132 monthly macroeconomic indicators that include income, industrial production, measure of capacity, employment and unemployment, prices relating to both consumer and producer goods and services, wages, inventories and orders, stock prices, interest rates for different maturities, exchange rates, money aggregates, consumer confidence, and so on. In the housing sector, this data set includes ten variables, housing starts for the US and the four census divisions, total new private housing units for the US, and residential building permits for the four census regions. To this data set, we add economy-wide mobile home shipments (US Census Bureau) and single-family existing home sales and their median prices for the four census regions and the US economy (National Association of Realtors). In total, we use 143 monthly series. Following Rapach and Strauss (2007, 2009), we convert house prices to real values by deflating with the personal consumption expenditure deflator. ${ }^{10}$ The data spans the period of 1968:01 through 2003:12. The start date coincides with data availability of home sales and prices, while the end date corresponds to the data set in Stock and Watson (2005). As in Banbura et al. (2010), we take logarithms for most of the series, except for those already in rates. In addition, for non-stationary variables, we set $\delta_{i}=1$, while for stationary variables, we use $\delta_{i}=0$, implying random walk and white noise priors, respectively. ${ }^{11}$

\section{ANALYSIS}

\section{A Priori Expectations}

The deregulation of the US savings and loan industry, the development of higher-risk debt, and certain government policies enabled financially weaker firms and individuals to raise funds that they could not raise prior to these changes. Financially weaker individuals could now purchase homes and financially weaker firms could purchase physical capital - as witnessed by the large increase in the share of capital expenditures undertaken by junk-rated firms from the mid 1970's to 2004. These financially weaker agents could 'operate at the margin' in the sense that any slight increase in the FFR could prevent them from meeting repayment schedules, cause bankruptcy, and lead to repossession of property (shown by a more than four-fold increase in the personal bankruptcy filings between 1984 and 2004), resulting in an increase in the relative supply of houses and a decrease in the price. Further, the rising ratio of debt to personal disposable income severely constrains the ability of individuals to meet repayment schedules in the face of rising interest rates.

\footnotetext{
${ }^{10}$ While the personal consumption (PCE) deflator comes from the calculation of real GDP, the Bureau of Economic Analysis also computes the PCE on a monthly basis. See Table 2.8.4. Price Indexes for Personal Consumption Expenditures at http://www.bea.gov/national/nipaweb/SelectTable.asp?Selected=N.

${ }^{11}$ Appendix A in Banbura et al. (2010) reports the description of the data set and the transformations and the specification of $\delta_{i}$ for each series, except, of course, for the 11 additional housing-related variables that we added. For mobile-home shipments, home sales, and prices, we take natural logarithms. We impose $\delta_{i}=0$ for mobile home shipments and $\delta_{i}=1$ for home sales and prices, given their time-series behavior.
} 
We, therefore, expect to see an increase in the sensitivity of house prices to a given shock in the FFR during the post-liberalization period. Furthermore, we expect the housing markets in the West and the South to drive the national housing data. These Sun-Belt states experienced relatively rapid migration and population growth over our sample period. In addition, the West's popularity and favorable climate led to higher house prices in comparison with prices in other parts of the country, suggesting that changes in house prices in the West should disproportionally influence the index of US house prices. We do not expect massive building in large parts of the Snow-Belt states in the Midwest and the East to drive the index of US house prices. In addition, the South also experiences significant building activity. To see if the Sun-Belt states in the West and South drive the US housing market and if house prices respond more quickly after financial liberalization, we turn to our impulse response function analysis. In other words, we consider which census region comes the closest to matching the findings at the national level.

\section{Impulse Response Function Analysis}

This section analyzes the effects of a monetary policy (FFR) shock on real house price of the four census regions and the aggregate US economy housing-market variables. For this purpose, following Christiano et al. (2005) and Bernanke et al. (2005), we identify the monetary shock based on a recursive identification scheme, categorizing the 143 variables as either slow- $\left(S_{t}\right)$ or fast-moving $\left(F_{t}\right)$ variables. Generally speaking, the former set includes real variables and prices, while the latter consists of financial variables. All housing-market variables, including the real house prices, appear in the slow-moving segment. Defining the monetary shock variable as $r_{t}$, we order the variables as follows: $Y_{t}=\left(S_{t}, r_{t}, F_{t}\right)$. The ordering embodies two key assumptions about identification: the variables in $F_{t}$ respond contemporaneously with the monetary shock, while the variables in $S_{t}$ do not. Moreover, we also assume that the FFR shock lies orthogonal to all other shocks driving the economy.

In our impulse response analysis, we increase contemporaneously the Federal funds rate by one hundred basis points. Following Canova (1991) and Gordon and Leeper (1994), we can easily compute the impulse response functions, given just identification, by generating draws from the posterior of $\left(A_{1}, \ldots \ldots . . A_{p}, \Psi\right)$.

Table 1 reports the impulse responses and Figures 1 and 2 provide the plots for the 4 regional real house prices and the aggregate real US house price based on the periods 1968:01 to 1982:12 and 1989:01 to 2003:12 obtained from a LBVAR with the modified Minnesota prior, estimated with $p=13$ and $\lambda=0.0465$ based on the desired fit. Note that since $\lambda$ is small, the prior restrictions play an important role in the estimation.

In Figures 1 and 2, we plot the behavior of the functions over 48 months following a monetary policy shock. Figure 1 shows the effect of 100-basis-point monetary policy shock on house price indexes with confidence bands to determine regions of significance during the period 1968 to 1982 and Figure 2 does the same for the period 1989 to 2003. In Figures 1 and 2, the shaded regions indicate the posterior coverage intervals corresponding to both 90 (lighter shaded region) and 68 (darker shaded region) percent levels of confidence.

Note from Table 1 and Figures 1 and 2, no evidence emerges of a home-price puzzle observed by McCarthy and Peach (2002), in either the pre- or post-liberalization periods. Gupta et al. (forthcoming) use the FAVAR approach, which also accommodates large number of economic variables, and find similar results. ${ }^{12}$ Figure 1 illustrates how a contractionary monetary policy drops the US house price index at national level during the preliberalization period (i.e., pre-1982). The Federal funds rate (FFR) increases by one percent and remains significant for about 15 months. ${ }^{13}$ House prices persist and remain significant for more than two years. Comparing regions, we can see that house prices in the Northeast (HPNE) and the Midwest (HPMW) show a strong, persistent response -

\footnotetext{
${ }^{12}$ Gupta and Kabundi (2010) conduct their quarterly dynamic analysis from 1976:01 through 2005:02 and do not indicate how the financial market liberalization in the early 1980s may affect those dynamics.

${ }^{13}$ We report all results based on the 68 percent level of significance. 
particularly in the Midwest where the responses remain significant for about 23 months, though the size of the effect in Northeast proves bigger. The response of house prices in the West (HPW) and the South (HPS) seem weak and short lived. Finally, the findings for the Midwest come closest to matching the national results, implying that the Midwest drives the US housing market in the pre-liberalization period.

Table 1 and Figure 2 show the effect of contractionary monetary policy on US house prices during the postliberalization period (i.e., 1989 to 2003). Table 1 shows that the effect of the monetary shock on the real house prices, both at the regional level and the national level, during the post-liberalization period exceed the effect in the pre-liberalization era. As in the pre-liberalization period, Figure 2 also displays the heterogeneous responses across regions in the US. House prices in the South (HPS) come closest to matching the national findings, implying that the South drives the national response. The West (HPW) shows a relatively weak, short-lived response. House prices in the Northeast (HPNE) and the Midwest (HPMW) exhibit identical responses -- relatively weak and short-lived -with the effect in the Northeast (HPNE) exceeding that in the West (HPW) and the Midwest (HPMW).

\section{CONCLUSIONS}

This paper assesses the effects of monetary policy on US house price indexes, national and regional, using impulse response functions obtained from a LBVAR model that incorporates 143 monthly macroeconomic variables during the pre-liberalization (i.e., 1968:01 to 1982:12) and post-liberalization (i.e., 1989:01 to 2003:12) periods. The housing variables include 21 series relating to housing starts, total new private housing units, mobile-home shipments, home sales, and home prices at the national level and housing starts, housing permits, home sales, and home prices in the four census regions (Northeast, Midwest, South, and West) of the US.

Our econometric analysis focuses on impulse response functions, given a 100-basis-point increase in the FFR. We compare the responses over two sub-samples to investigate the effect that financial market liberalization exerted on the sensitivity of house prices to changes in the interest rate. Overall, the 100 basis point FFR shock produces larger effects on the real house prices, both at the regional level and the national level, in the postliberalization period when compared to the pre-liberalization era. While the precision of the estimates do not imply significant differences, the finding does offer a caution. That is, the housing market appears more sensitive to monetary policy shocks in the post-liberalization period. On the one hand, this suggests that monetary policy possesses increased leverage. On the other hand, the housing market cycle traditionally contributes an important component to the aggregate business cycle. Thus, the monetary authorities may need to exercise more care in implementing Federal funds rate adjustments going forward. In addition, contractionary monetary policy exerts a negative effect on house prices at the national level, indicating the absence of price puzzle in small structural vector autoregressive models. The puzzles absence in the housing sector possibly emerges as a result of proper identification of monetary policy shocks within a data-rich environment.

At the national level, the negative effect of the monetary policy shock on house prices persists and remains significant for more than two years before liberalization, while after liberalization, prices recover rapidly in about one year. The reaction of the national housing sector proves heterogeneous across regions. Over time, certain dynamics change - the Midwest appears to drive house prices before 1982, the South emerges as the driving force behind the dynamics observed in national housing sector after 1989. That is, after 1989, the impulse responses in the South more closely match those of the national housing sector than the other regions. While the Northeast and the Midwest display similar responses in duration over the pre- and post-liberalization phases, the Northeast responds more strongly to the monetary policy shock. During both periods, the West shows a relatively weak, short-lived response.

Our findings may provide some insight to the current Great Recession, financial crisis, and collapse of house prices, although still too early to conduct empirical analysis. Future reregulation of the financial markets, especially in the housing market, may alter, once again, the responsiveness of house prices to monetary policy. Our findings suggest that more regulation and less liberal financial markets may make house prices less responsive to monetary policy. The severity of the Great Recession, the impotence of traditional monetary policy, and the adoption of quantitative easing by the Federal Reserve probably altered the responsiveness of house prices to monetary policy. Answering this last point will require the passage of time and the accumulation of more data. 


\section{ACKNOWLEDGEMENT}

We would like to thank Marta Banbura for providing us with the codes used in estimating the large-scale BVAR and her assistance with its implementation.

\section{AUTHOR INFORMATION}

Professor Rangan Gupta is currently a Professor at the Department of Economics, University of Pretoria. After having completed my Ph.D. in May 2005 from the Department of Economics, University of Connecticut, he joined the Department of Economics, University of Pretoria, as a Senior Lecturer in August 2005 and got promoted to an Associate Professor in July 2007. E-mail: rangan.gupta@up.ac.za.

Dr. Marius Jurgilas is an advisor in the research department of Norges Bank. He joined research department in June 2011. He has worked as an Economist at the Bank of England in London, UK from 2008 to 2011. Before joining the Bank, he was an assistant professor at Elon University (North Carolina, US), where he was teaching Money \& Banking and Business Statistics. He received his degrees in economics at the University of Connecticut (MA in 2003 and $\mathrm{PhD}$ in 2007).

Professor Stephen M. Miller is currently Professor of Economics and Department Chair in the Lee School of Business at the University of Nevada, Las Vegas (2001-). Previously, Professor of Economics and Department Head at the University of Connecticut (1970-2001). Also, Visiting Scholar at the Federal Reserve Bank of Boston for 5 months in 1978 and at the Congressional Budget Office for 12 months in 1987-1988. E-mail: stephen.miller@unlv.edu. Corresponding author.

Mr. Dylan van Wyk is a graduate student at the department of Economics, University of Pretoria. He is currently pursuing his $\mathrm{PhD}$ degree in Economics in the field of International Macroeconomics.

\section{REFERENCES}

1. Ahearne, A. G., Ammer, J., Doyle, B. M., Kole, L. S., and Martin, R. F., 2005. Monetary Policy and House Prices: A Cross-Country Study. Central Bank of Chile, Working Paper 344.

2. Banbura, M, Gianonne, D., and Reichlin, L., 2010. Large Bayesian Vector Auto Regressions. Journal of Applied Econometrics 25, 71-92.

3. Beck, N., King, G., and Zeng, L., 2000. Improving Quantitative Studies of International Conflict: A Conjecture. American Political Science Review 94, 21-36.

4. Beck, N., King, G., and Zeng, L., 2004. Theory and Evidence in International Conflict: A Response to de Marchi, Gelpi, and Grynaviski. American Political Science Review 98, 379-389.

5. Bernanke, B. S., and Gertler, M., 1995. Inside the Black Box: The Credit Channel of Monetary Policy Transmission. The Journal of Economic Perspectives 9, 27-48.

6. Bernanke, B. S., and Gertler, M., 1999. Monetary Policy and Asset Volatility. Federal Reserve Bank of Kansas City, Economic Review 84, 17-52.

7. Bernanke, B. S., Boivin, J., and Eliazs, P., 2005. Measuring the Effects of Monetary Policy: A Factor Augmented Vector Autoregressive (FAVAR) Approach. The Quarterly Journal of Economics 120, 387422.

8. Bloor, C., and Matheson, T., 2010. Analysing Shock Transmission in a Data-Rich Environment: A Large BVAR for New Zealand. Empirical Economics 39, 537-558.

9. Borio, C. E. V., Kennedy, N., and Prowse, S. D., 1994. Exploring Aggregate Asset Price Fluctuations Across Countries: Measurement, Determinants, and Monetary Policy Implications. BIS Economics Paper No. 40.

10. Clements, M, and Hendry, D. 1998. Forecasting Economic Time Series. New York: Cambridge University Press.

11. Canova, F., 1991. The Sources of Financial Crisis: Pre- and Post-Fed Evidence. International Economic Review 32, 689-713. 
12. Carlino, G. A., and DeFina, R. H., 1998. The Differential Regional Effects of Monetary Policy. The Review of Economics and Statistics 80, 572-587.

13. Carlino, G. A., and DeFina, R. H., 1999. Do States Respond Differently to Changes in Monetary Policy? Federal Reserve Bank of Philadelphia, Business Review, (July/August), 17-27.

14. Case, K., Shiller, R., and Quigley, J., 2005. Comparing Wealth Effects: The Stock Market Versus the Housing Market. Advances in Macroeconomics 5, 1-32.

15. Chowdhury, A., and Wheeler, M., 1993. The Housing Market, Macroeconomic Activity and Financial Innovation: An Empirical Analysis of US Data. Applied Economics 25, 1385-1392.

16. Christiano, L., Eichenbaum, M., Evans, C., 2005. Nominal Rigidities and the Dynamic Effects of a Shock to Monetary Policy. Journal of Political Economy 113, 1-45.

17. Clements, M. P., and Hendry, D. F., 1998. Forecasting Economic Processes. International Journal of Forecasting 14, 111-131.

18. Das, S., Gupta, R., and Kabundi, A., 2009. Could We Have Forecasted the Recent Downturn in the South African Housing Market? Journal of Housing Economics 18, 325-335.

19. Das, S., Gupta, R., and Kabundi, A., 2010. The Blessing of Dimensionality in Forecasting Real House Price Growth in the Nine Census Divisions of the US. Journal of Housing Research 19, 89-109.

20. Das, S., Gupta, R., and Kabundi, A., forthcoming. Is a DFM Well-Suited for Forecasting Regional House Price Inflation? Journal of Forecasting.

21. De Mol, C., Gianonne, D., and Reichlin, L., 2008. Forecasting Using a Large Number of Predictors: Is Bayesian Regression a Valid Alternative to Principal Components? Journal of Econometrics 146, 318-328.

22. Doan, T., Litterman, R., and Sims, C., 1984. Forecasting and Conditional Projections Using Realistic Prior Distributions. Econometric Reviews 3, 1-100.

23. Ewing, B. T., and Wang, Y., 2005. Single Housing Starts and Macroeconomic Activity: An Application of Generalized Impulse Response Analysis. Applied Economic Letters 12, 187-190.

24. Falk, B., 1986. Unanticipated Money-Supply Growth and Single-Family Housing Starts in the US: 19641983. Housing Finance Review 5, 15-23.

25. Ghent, A., 2009. Sticky Housing and the Real Effects of Monetary Policy. Working Paper, http://aux.zicklin.baruch.cuny.edu/ghent/research/.

26. Ghent, A., and Owyang, M., 2009. Is Housing the Business Cycle? Evidence from US Cities, Mimeo, Department of Real Estate, Zicklin School of Business, Baruch College, CUNY.

27. Gordon, D. B., and Leeper, E. M., 1994. The Dynamic Impacts of Monetary Policy: An Exercise in Tentative Identification. Journal of Political Economy 102, 1228-1247.

28. Green, R., 1997. Follow the Leader: How Changes in Residential and Non-Residential Investment Predict Changes in GDP. Real Estate Economics 25, 253-270.

29. Gupta, R., and Kabundi, A., 2010. The Effect of Monetary Policy on House Price Inflation: A Factor Augmented Vector Autoregression (FAVAR) Approach. Journal of Economic Studies 37, 616-626.

30. Gupta, R., Kabundi, A., and Miller, S. M. forthcoming. Forecasting the US Real House Price Index: Structural and Non-Structural Models with and without Fundamentals. Economic Modelling.

31. Gupta, R., Jurgilas, M. and Kabundi, A., 2010. The Effect of Monetary Policy on Real House Price Growth Rate in South Africa: A Factor Augmented Vector Autoregression (FAVAR) Approach. Economic Modelling 27, 315-323.

32. Iacoviello, M., 2002. House Prices and Business Cycles in Europe: A VAR Analysis. Department of Economics, Working Paper No. WP540, Boston College.

33. Iacoviello, M., 2005. House Prices, Borrowing Constraints, and Monetary Policy in the Business Cycle. American Economic Review 95, 739-764.

34. Iacoviello, M., and Minetti R., 2003. Financial Liberalisation and the Sensitivity of House Prices to Monetary Policy: Theory and Evidence. The Manchester School 71, 20-34.

35. Iacoviello, M., and Minetti R., 2008. The Credit Channel of Monetary Policy: Evidence from the Housing Market. Journal of Macroeconomics 30, 69-96.

36. Iacoviello, M., and Neri S., 2010. Housing Market Spillovers: Evidence from an Estimated DSGE Model. American Economic Journal: Macroeconomics 2, 125-164.

37. Jarociński, M., and Smets, F. R., 2008. House Prices and the Stance of Monetary Policy. Federal Reserve Bank of St. Louis Review July/August, 339-364. 
38. Kasai N., and Gupta R., 2010. Financial Liberalization and the Effectiveness of Monetary Policy on House Prices in South Africa. ICFAI Journal of Monetary Economics VIII, 59-74.

39. Kadiyala, K. R., and Karlsson, S., 1997. Numerical Methods for Estimation and Inference in Bayesian VAR Models. Journal of Applied Econometrics 12, 99-132.

40. Litterman, R. B. (1981). A Bayesian Procedure for Forecasting with Vector Autoregressions. Working Paper, Federal Reserve Bank of Minneapolis.

41. Litterman, R., 1986. Forecasting with Bayesian Vector Autoregressions - Five Years of Experience. Journal of Business and Economic Statistics 4, 25-38.

42. McCarthy, J., and Peach, R., 2002. Monetary Policy Transmission to Residential Investment. Federal Reserve Bank of New York Economic Policy Review, 139-158.

43. Rapach, D. E., and Strauss, J. K., 2007. Forecasting Real Housing Price Growth in the Eighth District States. Federal Reserve Bank of St. Louis, Regional Economic Development 3, 33-42.

44. Rapach, D. E., and Strauss, J. K., 2009. Differences in Housing Price Forecast Ability Across U.S. States. International Journal of Forecasting 25, 351-372.

45. Sims, C., 1992. Interpreting the Macroeconomic Time Series Facts: The Effects of Monetary Policy. European Economic Review 36, 975-1000.

46. Sims, C. A., and Zha, T., 1998. Bayesian Methods for Dynamic Multivariate Analysis. International Economic Review 39, 949-968.

47. Stock, J. H., and Watson, M. W., 2002. Macroeconomics Forecasting Using Diffusion Indexes. Journal of Business and Economic Statistics 20, 147-62.

48. Stock, J. H., and Watson, M. W., 2003. Forecasting Output and Inflation: The Role of Asset Prices. Journal of Economic Literature 41, 788-829.

49. Stock, J. H., and Watson, M. W., 2004. Combination Forecasts of Output Growth in a Seven-Country Data Set. Journal of Forecasting 23, 405-430.

50. Stock, J. H., and Watson, M, W., 2005. Implications of Dynamic Factor Models for VAR Analysis. National Bureau of Economic Research, Working Paper, 11467.

51. Vargas-Silva, C., 2008a. Monetary Policy and the US Housing Market: A VAR Analysis Imposing Sign Restrictions. Journal of Macroeconomics 30, 977-990

52. Vargas-Silva, C., 2008b. The Effect of Monetary Policy on Housing: A Factor-Augmented Vector Autoregression (FAVAR) Approach. Applied Economics Letters 15, 749 - 752.

53. Walsh, C.E., 2000. Monetary Theory and Policy. The MIT Press, Cambridge: Massachusetts. 
Table 1: Impulse Response Results - Pre- and Post-Liberalization

\begin{tabular}{|c|c|c|c|c|c|c|c|c|c|c|}
\hline \multirow[b]{2}{*}{ Periods } & \multicolumn{5}{|c|}{ Pre-Liberalization Impulses } & \multicolumn{5}{|c|}{ Post-Liberalization Impulses } \\
\hline & HPNE & HPMW & HPS & HPW & HPUS & HPNE & HPMW & HPS & HPW & HPUS \\
\hline $\mathbf{0}$ & 0.000 & 0.000 & 0.000 & 0.000 & 0.000 & 0.000 & 0.000 & 0.000 & 0.000 & 0.000 \\
\hline 1 & -0.207 & -0.088 & -0.025 & -0.121 & -0.080 & -0.005 & -0.336 & -0.673 & -0.105 & -0.450 \\
\hline 2 & -0.336 & -0.220 & -0.084 & -0.214 & -0.164 & -0.819 & -0.730 & -1.203 & -0.668 & -0.937 \\
\hline 3 & -0.411 & -0.323 & -0.180 & -0.240 & -0.249 & -1.372 & -1.008 & -1.337 & -1.069 & -1.184 \\
\hline 4 & -0.430 & -0.348 & -0.233 & -0.220 & -0.287 & -1.638 & -1.135 & -1.428 & -1.232 & -1.269 \\
\hline 5 & -0.383 & -0.339 & -0.243 & -0.221 & -0.292 & -1.748 & -1.200 & -1.494 & -1.312 & -1.312 \\
\hline 6 & -0.354 & -0.319 & -0.218 & -0.224 & -0.282 & -1.842 & -1.225 & -1.440 & -1.146 & -1.277 \\
\hline 7 & -0.348 & -0.286 & -0.171 & -0.222 & -0.261 & -1.857 & -1.208 & -1.376 & -0.988 & -1.212 \\
\hline 8 & -0.346 & -0.255 & -0.127 & -0.222 & -0.237 & -1.762 & -1.149 & -1.304 & -0.894 & -1.122 \\
\hline 9 & -0.347 & -0.231 & -0.104 & -0.227 & -0.222 & -1.587 & -1.037 & -1.210 & -0.798 & -1.002 \\
\hline 10 & -0.363 & -0.224 & -0.098 & -0.245 & -0.222 & -1.442 & -0.926 & -1.135 & -0.707 & -0.898 \\
\hline 11 & -0.384 & -0.236 & -0.109 & -0.271 & -0.236 & -1.310 & -0.844 & -1.076 & -0.691 & -0.828 \\
\hline 12 & -0.413 & -0.258 & -0.137 & -0.297 & -0.262 & -1.161 & -0.788 & -1.024 & -0.702 & -0.770 \\
\hline 13 & -0.441 & -0.280 & -0.172 & -0.317 & -0.290 & -1.067 & -0.756 & -1.011 & -0.721 & -0.738 \\
\hline 14 & -0.461 & -0.300 & -0.204 & -0.334 & -0.314 & -1.037 & -0.759 & -1.020 & -0.746 & -0.732 \\
\hline 15 & -0.474 & -0.315 & -0.226 & -0.345 & -0.332 & -1.053 & -0.794 & -1.047 & -0.774 & -0.749 \\
\hline 16 & -0.482 & -0.323 & -0.238 & -0.348 & -0.342 & -1.096 & -0.848 & -1.089 & -0.803 & -0.782 \\
\hline 17 & -0.485 & -0.325 & -0.240 & -0.347 & -0.345 & -1.151 & -0.904 & -1.136 & -0.833 & -0.824 \\
\hline 18 & -0.483 & -0.324 & -0.237 & -0.346 & -0.344 & -1.203 & -0.949 & -1.178 & -0.860 & -0.862 \\
\hline 19 & -0.479 & -0.320 & -0.231 & -0.345 & -0.341 & -1.241 & -0.975 & -1.208 & -0.884 & -0.891 \\
\hline 20 & -0.475 & -0.316 & -0.225 & -0.347 & -0.338 & -1.257 & -0.982 & -1.227 & -0.907 & -0.907 \\
\hline 21 & -0.474 & -0.312 & -0.220 & -0.349 & -0.336 & -1.257 & -0.975 & -1.235 & -0.929 & -0.913 \\
\hline 22 & -0.475 & -0.308 & -0.217 & -0.351 & -0.334 & -1.248 & -0.961 & -1.237 & -0.951 & -0.913 \\
\hline 23 & -0.477 & -0.305 & -0.215 & -0.353 & -0.333 & -1.236 & -0.945 & -1.238 & -0.975 & -0.911 \\
\hline 24 & -0.481 & -0.303 & -0.214 & -0.355 & -0.332 & -1.225 & -0.933 & -1.241 & -1.001 & -0.911 \\
\hline 25 & -0.484 & -0.301 & -0.212 & -0.355 & -0.331 & -1.218 & -0.926 & -1.248 & -1.030 & -0.912 \\
\hline 26 & -0.487 & -0.298 & -0.209 & -0.353 & -0.330 & -1.215 & -0.923 & -1.257 & -1.058 & -0.917 \\
\hline 27 & -0.489 & -0.294 & -0.204 & -0.351 & -0.326 & -1.215 & -0.924 & -1.270 & -1.087 & -0.922 \\
\hline 28 & -0.490 & -0.289 & -0.199 & -0.347 & -0.322 & -1.216 & -0.927 & -1.283 & -1.113 & -0.928 \\
\hline 29 & -0.490 & -0.284 & -0.192 & -0.343 & -0.317 & -1.215 & -0.930 & -1.296 & -1.138 & -0.933 \\
\hline 30 & -0.490 & -0.278 & -0.184 & -0.338 & -0.311 & -1.212 & -0.933 & -1.309 & -1.159 & -0.937 \\
\hline 31 & -0.489 & -0.272 & -0.176 & -0.333 & -0.304 & -1.205 & -0.936 & -1.322 & -1.177 & -0.939 \\
\hline 32 & -0.487 & -0.267 & -0.167 & -0.328 & -0.297 & -1.195 & -0.938 & -1.335 & -1.192 & -0.940 \\
\hline 33 & -0.486 & -0.262 & -0.158 & -0.323 & -0.291 & -1.183 & -0.940 & -1.349 & -1.205 & -0.940 \\
\hline 34 & -0.484 & -0.257 & -0.150 & -0.319 & -0.284 & -1.169 & -0.942 & -1.364 & -1.217 & -0.940 \\
\hline 35 & -0.482 & -0.252 & -0.141 & -0.315 & -0.277 & -1.155 & -0.946 & -1.381 & -1.227 & -0.940 \\
\hline 36 & -0.481 & -0.248 & -0.132 & -0.311 & -0.270 & -1.140 & -0.950 & -1.400 & -1.237 & -0.942 \\
\hline 37 & -0.479 & -0.244 & -0.123 & -0.307 & -0.263 & -1.127 & -0.956 & -1.421 & -1.246 & -0.944 \\
\hline 38 & -0.477 & -0.240 & -0.114 & -0.304 & -0.257 & -1.115 & -0.963 & -1.445 & -1.255 & -0.948 \\
\hline 39 & -0.475 & -0.236 & -0.105 & -0.302 & -0.250 & -1.105 & -0.971 & -1.471 & -1.263 & -0.953 \\
\hline 40 & -0.473 & -0.233 & -0.096 & -0.299 & -0.244 & -1.097 & -0.980 & -1.498 & -1.272 & -0.960 \\
\hline 41 & -0.470 & -0.230 & -0.088 & -0.297 & -0.238 & -1.091 & -0.991 & -1.528 & -1.280 & -0.967 \\
\hline 42 & -0.468 & -0.228 & -0.079 & -0.296 & -0.232 & -1.087 & -1.003 & -1.559 & -1.288 & -0.977 \\
\hline 43 & -0.466 & -0.226 & -0.071 & -0.295 & -0.226 & -1.086 & -1.015 & -1.592 & -1.296 & -0.987 \\
\hline 44 & -0.464 & -0.224 & -0.063 & -0.294 & -0.221 & -1.087 & -1.027 & -1.625 & -1.305 & -0.998 \\
\hline 45 & -0.463 & -0.223 & -0.055 & -0.293 & -0.215 & -1.090 & -1.039 & -1.659 & -1.313 & -1.009 \\
\hline 46 & -0.461 & -0.221 & -0.048 & -0.293 & -0.211 & -1.095 & -1.051 & -1.694 & -1.321 & -1.022 \\
\hline 47 & -0.459 & -0.220 & -0.041 & -0.293 & -0.206 & -1.102 & -1.063 & -1.728 & -1.329 & -1.034 \\
\hline 48 & -0.458 & -0.220 & -0.034 & -0.293 & -0.202 & -1.111 & -1.075 & -1.763 & -1.338 & -1.047 \\
\hline
\end{tabular}

Note: The 0 - to 48 -month ahead impulse responses. 
Figure 1: Effect of 100-Basis-Point Monetary Policy Shock on House Price Indexes with Confidence Bands: 1968 - 1982 Note: $\mathrm{X}$-axis measures the number of months and $\mathrm{Y}$-axis measures the percentage change in the specific variable.
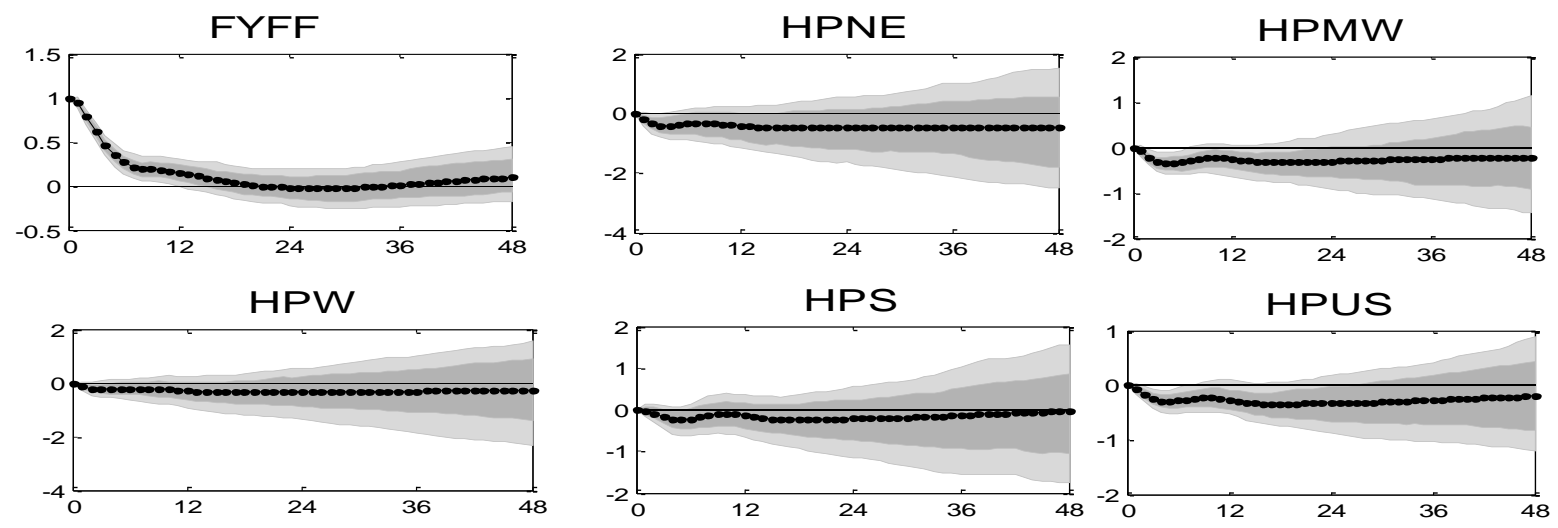

Figure 2: Effect of 100-Basis-Point Monetary Policy Shock on House Price Indexes with Confidence Bands: 1989 - 2003 Note: $\mathrm{X}$-axis measures the number of months and $\mathrm{Y}$-axis measures the percentage change in the specific variable.
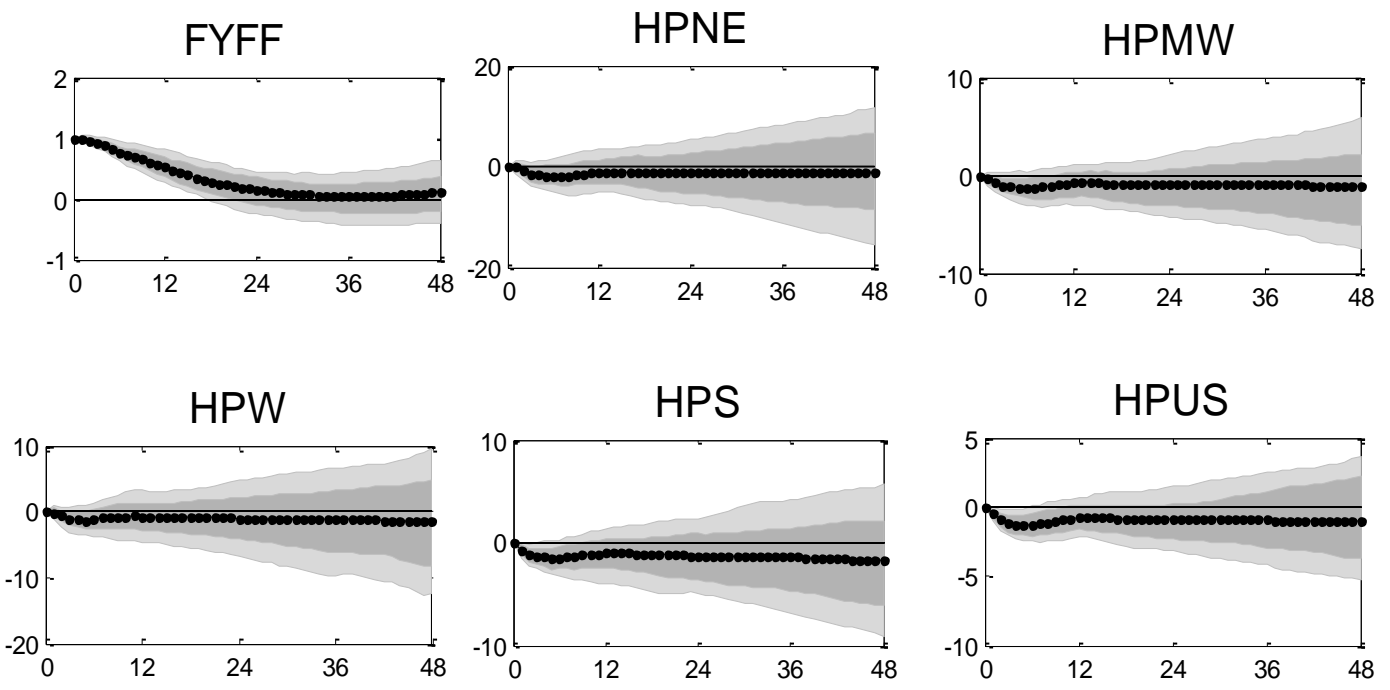
NOTES 